\title{
openheart The effect of bivalirudin and closure device on bleeding outcomes after percutaneous coronary interventions
}

\author{
David R Dobies, ${ }^{1}$ Kimberly R Barber, ${ }^{2}$ Amanda L Cohoon ${ }^{3}$
}

To cite: Dobies DR Barber KR, Cohoon AL. The effect of bivalirudin and closure device on bleeding outcomes after percutaneous coronary interventions. Open Heart 2014;1:e000087. doi:10.1136/openhrt-2014000087

Received 24 February 2014 Revised 20 June 2014 Accepted 15 July 2014
CrossMark

\footnotetext{
${ }^{1}$ Department of Cardiology, Regional Cardiology Associates, Grand Blanc, Michigan, USA

${ }^{2}$ Clinical Research, Genesys Regional Medical Center, Office of Research, Grand Blanc, Michigan, USA

${ }^{3}$ Cardiac Catheterization Laboratory, Genesys Regional Medical Center, Grand Blanc, Michigan, USA

Correspondence to Professor Kimberly R Barber; kbarber@genesys.org
}

\begin{abstract}
Introduction: Studies have demonstrated bivalirudin efficacy in some patients at increased risk of bleeding. The aim of this study was to determine the extent to which bleeding reduction is achieved among all patients using bivalirudin as compared with a heparin with or without 2B3A inhibitor strategy.

Methods: This is a real-world, large-scale retrospective study utilising the American College of Cardiology (ACC) data from a 37-hospital Ascension Health System. The registry represents routine clinical practice between 1 June 2009 and 30 June 2012. End points included major bleeding, major adverse cardiac events and death. Multivariate regression analysis modelled on predictors of end points.
\end{abstract}

Results: This study included $58862 \mathrm{PCl}$ procedures. Major bleeding rates were lowest for bivalirudin plus closure device overall $(\mathrm{OR}=0.53, \mathrm{Cl} 0.21$ to 0.84 , $p=0.001$ ). The use of a device for access closure contributed to the greatest declines in major bleeding. Compared with heparin with device, bivalirudin with device had a significantly lower rate of bleeding $(\mathrm{OR}=0.37, \mathrm{Cl} 0.18$ to $0.74, p=0.005)$. The use of device had a greater effect on decreasing bleeding among patients receiving bivalirudin compared with heparin, especially among women $(p=0.001)$. After adjustment for 2B3A use, this advantage was no longer significant in ST segment elevation myocardial infarction patients $(\mathrm{OR}=1.8, \mathrm{Cl} 0.5$ to $6.0, \mathrm{p}=0.34$ ).

Conclusions: All risk groups in this real world database representing current clinical practice benefited from the use of bivalirudin and device closure with lower risk groups benefiting the most. This robust analysis of real-world clinical data supports a combined treatment strategy of bivalirudin and closure device.

\section{INTRODUCTION}

Heparin has been the standard anticoagulant for percutaneous coronary intervention (PCI) since the first PCI was performed. In the current era of coronary interventions, bivalirudin and groin closure by device have made an impact on bleeding complications related to PCI. ${ }^{1-3}$ For ischaemic clinical end

\section{KEY MESSAGES}

What is already known about this subject?

- Bivalirudin is beneficial in STEMI and Non STEMI patients.

What does this study add?

- That bivalirudin is beneficial, when compared to heparin, in lower risk patients (eg, patients with negative troponin).

How might this impact on clinical practice?

- The evidence from real world clinical practice data suggests that bivalirudin is beneficial even in elective patients and should be considered for low, as well as, high risk patients undergoing $\mathrm{PCI}$.

points, bivalirudin has been shown to be effective in lowering major and minor bleeding complications for patients of moderate risk. $^{4-6}$ More recently, bivalirudin demonstrated a reduction in 1 year mortality and recurring myocardial infarction (MI) compared with heparin+glycoprotein IIb/IIIa inhibitor among high risk patients. ${ }^{7}$ Bivalirudin performance across different clinical and interventional settings (High risk ST segment elevation MI (STEMI), PCI, acute coronary syndrome) has been established in regards to decreasing PCI-related bleeding and bleeding-related outcomes. ${ }^{8-14}$

Bivalirudin as the sole antithrombotic strategy for high-risk PCI patients and for preferential treatment strategies based on risk modelling has become popular in the medical literature. ${ }^{8}{ }^{12-14}$ Although bivalirudin is effective in reducing bleeding among moderate risk groups and in improved ischaemic outcomes for high-risk groups, studies have not adequately examined their impact among lower risk (non-STEMI (NSTEMI)) elective PCI patients. The aim of this study was to compare in-hospital major bleeding outcomes in risk-stratified $\mathrm{PCI}$ patients receiving bivalirudin versus unfractionated heparin with and without access device closure. 


\section{METHODS}

\section{Study design and population}

This is a real-world, large-scale retrospective study utilising data from a 37-hopsital Ascension Health System (AHS) registry. A central repository was initiated with mandatory reporting of 84 well-established data points defined by the American College of Cardiology/ American Heart Association (ACC/AHA) Guidelines on Key Data Elements. ${ }^{15}$ Data were entered prospectively by trained personnel at the time of the heart catheterisation for consecutive patients from all hospitals performing catheterisation in this healthcare system. The database is routinely audited for accuracy and completeness. All patients undergoing a cardiac catheterisation procedure were included in the database. No patients are excluded. The registry represents procedures and devices as used in routine practice per operator discretion. The most recent 3-year period from 1 June 2009 to 30 June 2012 is included in this study.

\section{Data collection}

Clinical variables collected for the study included demographics, clinical data, devices, intraprocedure and postprocedure events, access site, closure method (all devices, extravascular and intravascular, were grouped together and compression includes manual and mechanical), and discharge status. End points were defined according to the ACC. ${ }^{15}$ The data in this AHS registry are directly reported from the procedure to the registry. This AHS registry reflects current clinical practice at community hospitals in the USA.

\section{Measurements}

The primary end point included complications of major bleeding. Major bleeding included events of bleeding within $72 \mathrm{~h}$ postprocedure, with at least one of the following: haemoglobin drop $\geq 3 \mathrm{~g} / \mathrm{dL}$, transfusion of whole blood or pack red blood cells, and procedural/ surgical intervention at the bleed site. All significant complications are captured by the registry.

\section{Statistical analysis}

Outcomes were compared between anticoagulant therapy groups (heparin vs bivalirudin adjusted for 2B3A inhibitors) and access closure approaches (any device vs manual or mechanical compression). Sample size determination for increased efficacy of device closure over compression was based on an estimated incidence of the primary end point of $2 \%$ in the compression group with a $25 \%$ decreased rate in the device group. A sample size of at least 40000 procedures was planned. A trial of this size has $90 \%$ power at an $\alpha$ level of 0.01 to show a decrease in incidence of the primary end point from $2 \%$ to $1.5 \%$ as significant. Statistical analysis was performed using the Statistical Package for the Social Sciences, V.18.0 (SPSS, Inc, Chicago, Illinois, USA).

Continuous data were expressed as mean $\pm \mathrm{SD}$ and categorical data as percentages. Differences between groups with continuous data were performed by independent $\mathrm{t}$ test and for categorical data, by $\chi^{2}$ analysis and OR. Linear relationships of continuous data to outcome measures were derived by logistic regression modelling adjusting for differences in baseline characteristics observed between groups that potentially influence the outcome of interest. Multivariate logistic regression modelling was used to determine factors independently associated with each outcome. Initial modelling included containing and controlling for potential confounders and interaction terms. The initial model loaded all of the variables into a forward stepwise regression with the variable entry rule set at 0.05 and the removal rule set at 0.10 . Interaction terms for closure method and anticoagulant were included. The effect of anticoagulant, and closure method, was tested according to risk groups by stratification. 2B3A inhibitors were retained within the model. The relative contribution of each measure in the outcome prediction was estimated by the relative increase or decrease of the $\beta$ with the addition of each variable by stepwise fashion. The study was approved and conducted under the regulations of the health system institutional review board. No extramural funding was used to support this work. The authors are solely responsible for the design and conduct of this study, its analysis, and the drafting of the paper, as well as, its final contents.

\section{RESULTS}

A total of 93282 catheterisation procedures were included in the database. Of these, $58862(63.1 \%)$ were PCI. Elective ( $\mathrm{n}=23 \mathrm{837}, 40.5 \%)$, urgent $(\mathrm{n}=26513,45.0 \%)$, and emergent $(n=8348,14.2 \%)$ and are included in this analysis. There were $47.7 \%(\mathrm{n}=28088)$ patients with Unstable Angina (UA) /NSTEMI, $13.5 \%(\mathrm{n}=7948)$ with STEMI, and $33.1 \%(\mathrm{~N}=19468)$ other. The majority was male $(\mathrm{n}=39379$ or $66.9 \%)$, Caucasian $(\mathrm{n}=53663$ or $91.2 \%)$, and the average age was 64.5 years (SD: 12.0). Current smokers accounted for $29.6 \%(\mathrm{n}=17430)$ and almost half had a previous intervention ( $\mathrm{n}=26913$ or $45.7 \%)$. The mean body mass index (BMI) was 30.6 (SD: 10.8) with $33 \%$ ( $\mathrm{n}=19$ 406) above 32 (obese).

Compression closure occurred in $81.1 \%(n=47721)$ of procedures followed by device closure $(n=11141$ or $18.9 \%)$. The femoral artery accounted for the majority of arterial sites accessed ( $\mathrm{n}=55781$ or $94.8 \%$ ) followed by $2751(4.7 \%)$ radial and $220(0.4 \%)$ brachial. There were $20808(35.4 \%)$ patients treated with bivalirudin and $38008(64.5 \%)$ treated with unfractionated heparin (with and without 2B3A inhibitors). Patient demographics and procedural characteristics overall and by anticoagulant group are presented in table 1 .

\section{Risk factor analysis}

The following analysis is confined to femoral procedures only $(\mathrm{n}=55781)$. Patients at higher risk of bleeding included STEMI patients, women, older age, current 
Table 1 Baseline characteristics by anticoagulant group

\begin{tabular}{|c|c|c|c|c|}
\hline Factor & $\begin{array}{l}\mathrm{PCl} \text { group }(\mathrm{N}=58 \mathrm{862}) \\
\mathrm{n}(\%)\end{array}$ & $\begin{array}{l}\text { Bivalirudin ( } \mathrm{N}=20 \text { 808) } \\
\text { n (\%) }\end{array}$ & $\begin{array}{l}\text { Heparin }(\mathrm{N}=38008) \\
\mathrm{n}(\%)\end{array}$ & p Value \\
\hline \multicolumn{5}{|l|}{ Gender } \\
\hline \multicolumn{5}{|l|}{ Age group } \\
\hline$>65$ year & $27700(47.1)$ & $10421(50.1)$ & $17279(45.5)$ & $<0.001$ \\
\hline \multicolumn{5}{|l|}{ Race } \\
\hline Mean (SD) & $30.6(10.5)$ & $30.6(9.4)$ & $30.7(11.5)$ & 0.25 \\
\hline HTN & 49897 (84.7) & $18174(87.5)$ & 31723 (83.6) & $<0.001$ \\
\hline Dyslipidemia & $50331(85.5)$ & $18298(88.1)$ & 32033 (84.4) & $<0.001$ \\
\hline Current smoker & $17416(29.6)$ & 5455 (26.3) & 11961 (31.5) & $<0.001$ \\
\hline Prior MI & $20873(35.5)$ & 7722 (37.1) & 13151 (34.6) & $<0.001$ \\
\hline Kidney disease & $1067(1.8)$ & $378(1.8)$ & $689(1.8)$ & 1.0 \\
\hline Prior CVD & 22681 (38.5) & $17636(15.1)$ & 5045 (13.3) & $<0.001$ \\
\hline Prior PAD & $8304(14.1)$ & 3267 (15.7) & 5037 (13.3) & $<0.001$ \\
\hline Chronic lung disease & $11112(18.9)$ & 4060 (19.5) & 7052 (18.6) & 0.01 \\
\hline Diabetes & 22562 (38.3) & $8352(40.1)$ & $14210(37.4)$ & $<0.001$ \\
\hline Device closure & $10890(18.5)$ & 4497 (21.6) & $6393(16.8)$ & $<0.001$ \\
\hline Gp2B3A & $17486(29.7)$ & $1621(7.8)$ & $15862(41.7)$ & $<0.001$ \\
\hline
\end{tabular}

smokers, those with a history of heart disease, diabetes, with kidney disease, with lung disease (table 2).

Those with BMI greater than 27, dyslipidemia, prior MI, or a prior procedure were at decreased risk of bleeding. After controlling for age; only gender, lung disease, kidney disease, and current smoking remained significant predictors of major bleeding complications. Women were at 2.4 times a greater risk then men after adjustment $(\mathrm{OR}=2.4$, CI 2.2 to 2.8, $\mathrm{p}=0.000)$. Their higher risk held for each of the risk categories (table 3).

Normal BMI $(\leq 27)$ was associated with less bleeding than overweight/obese BMI (>27). Female gender remained a highly significant, independent predictor of bleeding risk regardless of age, BMI or smoking. The unique contribution of female gender, controlling for age and BMI, explained a majority of the risk $\left(\mathrm{R}^{2}=77 \%\right.$, $\mathrm{OR}=2.2$, CI 1.9 to $2.5, \mathrm{p}<0.001)$. Kidney disease was the second most significant predictor of bleeding risk $\left(\mathrm{R}^{2}=62 \%, \mathrm{OR}=1.8\right.$, CI 1.3 to $\left.2.7, \mathrm{p}<0.001\right)$.

\section{Treatment effect analysis}

Univariate analysis

On univariate analysis, bivalirudin demonstrated a decreased major bleeding rate compared with heparin $(1.7 \%$ vs $2.5 \%$ respectively, $\mathrm{p}=0.000)$. This equates to a $32 \%$ relative risk $(\mathrm{RR})$ difference in bleeding $(\mathrm{RR}=0.66$, CI 0.58 to 0.75 ; figure 1 ). Stratified by PCI indication, the anticoagulant differential favoured bivalirudin for each indication but was only significant for NSTEMI patients. Among STEMI patients the bleeding rates for bivalirudin versus heparin were $5.2 \%$ vs $5.9 \% \quad(\mathrm{p}=0.349)$, among NSTEMI patients they were $1.7 \%$ vs $2.1 \%$ $(\mathrm{p}=0.046)$, and among Stable Angina patients they were $1.1 \%$ vs $1.3 \% \quad(p=0.45)$.

2B3A inhibitors demonstrated a potent effect on bleeding rates regardless of anticoagulant or PCI indication. On univariate analysis, we observed 2.5-4 times the bleeding rates for patients having 2B3A inhibitors on board depending on PCI indication (4.3\% vs $1.3 \%$, $\mathrm{RR}=3.3$, CI 2.9 to $3.8, \mathrm{p}=0.000$ ) (table 4). The lowest bleeding rate for women was the combination of bivalirudin and device which is a $59 \%$ relative drop in bleeding. Men also had their lowest rates of bleeding in the bivalirudin and device combination but the magnitude of the decline was much smaller than that for women.

A majority of STEMI patients received 2B3A inhibitors $(n=5195,67.5 \%)$ and most of the 2B3A inhibitors were given with heparin $(n=4828,92.9 \%)$. The 2B3A rate overall among patients receiving bivalirudin was $8.1 \%$ $(n=1590)$ and by indication the $2 \mathrm{~B} 3 \mathrm{~A}$ rate by anticoagulant was: STEMI (heparin $74.6 \%$, bivalirudin $30.2 \%$ ), NSTEMI (heparin 37\%, bivalirudin 7.6\%) and Stable Angina (heparin 31.5\%, bivalirudin 5.7\%). Among STEMI patients, bleeding rates for patients receiving 
Table 2 Baseline rates of bleeding by patient characteristics

\begin{tabular}{|c|c|c|c|}
\hline Factor & Major bleed, N (\%) & OR (Cl) & p Value \\
\hline \multicolumn{4}{|l|}{ Gender } \\
\hline Male & $565(1.4)$ & 2.5 (2.3 to 2.9$)$ & $<0.001$ \\
\hline Female & 699 (3.6) & & \\
\hline \multicolumn{4}{|l|}{ Age } \\
\hline$\leq 65$ & $492(1.6)$ & 1.8 (1.6 to 2.0$)$ & $<0.001$ \\
\hline$\geq 66$ & $772(2.8)$ & & \\
\hline \multicolumn{4}{|l|}{$\mathrm{BMI}$} \\
\hline$\leq 27$ & $517(2.7)$ & 0.7 (0.6 to 0.8$)$ & $<0.001$ \\
\hline$>27$ & 724 (1.9) & & \\
\hline \multicolumn{4}{|l|}{ HTN } \\
\hline No & $185(2.1)$ & $1.0(0.9$ to 1.2$)$ & 0.72 \\
\hline Yes & 1076 (2.2) & & \\
\hline \multicolumn{4}{|l|}{ Dyslipidemia } \\
\hline No & $252(3.0)$ & 0.7 (0.6 to 0.8$)$ & $<0.001$ \\
\hline Yes & $1009(2.0)$ & & \\
\hline \multicolumn{4}{|l|}{ Diabetes } \\
\hline No & $813(2.2)$ & $0.9(0.8$ to 1.0$)$ & 0.04 \\
\hline Yes & $450(2.0)$ & & \\
\hline \multicolumn{4}{|l|}{ Prior MI } \\
\hline No & $907(2.4)$ & 0.7 (0.6 to 0.8$)$ & $<0.001$ \\
\hline Yes & $357(1.7)$ & & \\
\hline \multicolumn{4}{|l|}{ Prior $\mathrm{CHF}$} \\
\hline No & $1029(2.0)$ & $1.4(1.2$ to 1.6$)$ & $<0.001$ \\
\hline Yes & $232(2.8)$ & & \\
\hline \multicolumn{4}{|l|}{ Prior PAD } \\
\hline No & $1033(2.0)$ & $1.3(1.2$ to 1.6$)$ & $<0.001$ \\
\hline Yes & $228(2.7)$ & & \\
\hline \multicolumn{4}{|l|}{ Current smoker } \\
\hline No & $855(2.1)$ & 1.1 (1.0 to 1.3$)$ & 0.05 \\
\hline Yes & $406(2.3)$ & & \\
\hline \multicolumn{4}{|l|}{ Kidney disease } \\
\hline No & $1220(2.1)$ & $1.7(1.2$ to 2.4$)$ & 0.002 \\
\hline Yes & $38(3.6)$ & & \\
\hline \multicolumn{4}{|l|}{ Lung disease } \\
\hline No & 905 (1.9) & 1.7 (1.5 to 1.9$)$ & $<0.001$ \\
\hline Yes & 356 (3.2) & & \\
\hline \multicolumn{4}{|l|}{ Prior $\mathrm{PCl}$} \\
\hline No & $899(2.8)$ & 0.47 (0.42 to 0.54$)$ & $<0.001$ \\
\hline Yes & $365(1.4)$ & & \\
\hline \multicolumn{4}{|l|}{ Prior CABG } \\
\hline No & $1077(2.3)$ & 0.64 (0.55 to 0.75$)$ & $<0.001$ \\
\hline Yes & $187(1.5)$ & & \\
\hline \multicolumn{4}{|l|}{ Indication } \\
\hline STEMI & $458(5.8)$ & 3.03 (2.6 to 3.4$)$ & $<0.001$ \\
\hline Non-STEMI & $534(1.9)$ & & \\
\hline \multicolumn{4}{|l|}{ Closure } \\
\hline Compression & $892(2.4)$ & $0.8(0.7$ to 1.0$)$ & 0.005 \\
\hline Device & $118(1.9)$ & & \\
\hline \multicolumn{4}{|l|}{ Anticoagulant } \\
\hline Heparin & $922(2.4)$ & 0.7 (0.6 to 0.7$)$ & $<0.001$ \\
\hline Bivalirudin & $340(1.6)$ & & \\
\hline
\end{tabular}

2B3A inhibitors or not were $6.9 \%$ vs $3.6 \%$ ( $R R=2.0$, CI 1.6 to $2.5, \mathrm{p}=0.000$ ). Among NSTEMI patients, bleeding rates were $3.6 \%$ vs $1.4 \%$, respectively, $(\mathrm{RR}=2.7$, CI 2.3 to $3.2, \mathrm{p}=0.000)$ and among Stable Angina patients, bleeding rates were $2.3 \%$ vs $0.9 \%$ respectively $(\mathrm{RR}=2.5$, CI 1.9 to $3.2, \mathrm{p}=0.000$ ). Of note, is that even among patients with Stable Angina for whom 20.0\% ( $\mathrm{n}=4386)$ received 2B3A inhibitors, bleeding rates were increased a relative $60.8 \%$ (2.6 times) compared with those not receiving them. 


\begin{tabular}{|c|c|c|c|c|}
\hline & Male, n (\%) & Female, n (\%) & OR (CI) for gender & p Value \\
\hline 2B3A inhibitors $(n=16739)$ & $344(3.0)$ & $373(7.0)$ & $2.4(2.1$ to 2.8$)$ & 0.000 \\
\hline STEMI $(n=5194)$ & $193(5.2)$ & $165(11.1)$ & $2.2(1.8$ to 2.8$)$ & 0.000 \\
\hline NSTEMI $(\mathrm{n}=7152)$ & $113(2.4)$ & $146(6.2)$ & 2.7 (2.1 to 3.5$)$ & 0.000 \\
\hline Stable angina $(n=4386)$ & $38(1.3)$ & $62(4.2)$ & $3.3(2.2$ to 5.0$)$ & 0.000 \\
\hline No 2B3A inhibitors ( $n=38$ 992) & $204(0.8)$ & $311(2.4)$ & $3.0(2.5$ to 3.6$)$ & 0.000 \\
\hline STEMI $(n=2474)$ & $48(2.9)$ & $40(5.0)$ & $1.7(1.2$ to 2.7$)$ & 0.01 \\
\hline NSTEMI $(n=19320)$ & $92(0.7)$ & $173(2.6)$ & 3.5 (2.8 to 4.6$)$ & 0.000 \\
\hline Stable Angina $(n=17178)$ & $64(0.6)$ & $98(1.7)$ & $3.2(2.3$ to 4.4$)$ & 0.000 \\
\hline
\end{tabular}

When the addition of 2B3A inhibitors and PCI indication were taken into account, the benefit of bivalirudin is no longer evident in the univariate analysis (figure 2). Across all indications, bleeding rates between bivalirudin and heparin were similar and/or did not differ significantly regardless of 2B3A inhibition. However, these rates do not control for other patient characteristics that differ by anticoagulant. We controlled for these in the multivariate analysis.

\section{Multiple regression analysis}

Many patient factors differed significantly between those receiving bivalirudin and heparin (table 1 ). These factors were controlled in a multivariable logistic regression analysis. The initial regression resulted in several factors not predictive of major bleeding (race, dyslipidemia, prior acute MI, prior coronary artery bypass grafting). The final regression analysis is shown in table 5 . Female sex was an independent significant predictor of bleeding ( $\mathrm{OR}=2.1$, CI 1.9 to 2.4, $\mathrm{p}=0.000)$. It contributed the most, of patient characteristics, to this model for risk of bleeding $(\mathrm{B}=0.75)$. Although older age was a significant predictor of bleeding, when controlling for other factors, it contributed little to the risk differential $(\mathrm{B}=0.033)$. Prior $\mathrm{PCI}$ was a strong predictor $(\mathrm{B}=0.73)$ of lower risk of bleeding $(\mathrm{OR}=0.57$, CI 0.49 to 0.65 , $\mathrm{p}=0.000)$. Kidney disease $(\mathrm{B}=0.62)$ and lung disease $(\mathrm{B}=0.49)$ were both significant independent predictors

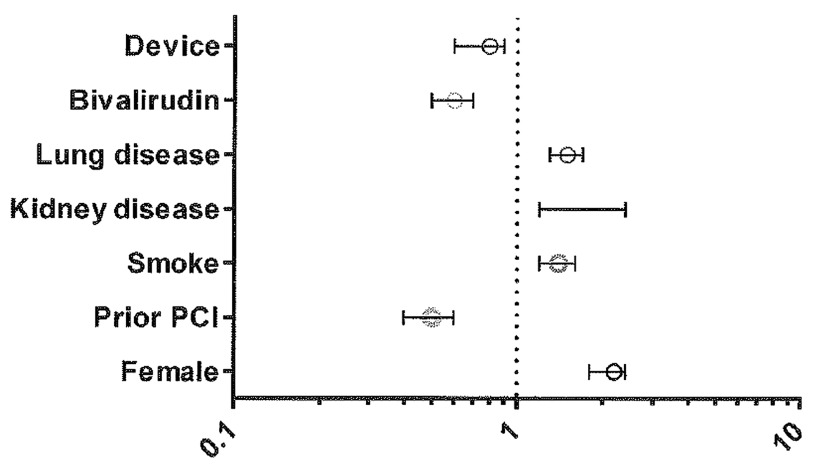

Figure 1 Predictors of major bleeding outcomes-treatment effect of bivalirudin compared to heparin controlling for age, body mass index, indication and comorbid conditions. of bleeding in the model. All other factors were either not significant or contributed little to the risk differential.

2B3A inhibition was a strong, independent predictor of increased risk of bleeding ( $\mathrm{OR}=3.4$, CI 2.9 to 3.9, $\mathrm{p}=0.000$ ). In addition, bivalirudin was a significant independent predictor of lower risk $(\mathrm{OR}=0.38$, CI 0.19 to $0.76, \mathrm{p}=0.01)$. Closure device did not show a significant association to bleeding risk $(p=0.11)$. However, we did observe a significant interaction between closure device and anticoagulant ( $\mathrm{p}=0.003$; figure 3 ).

The regression analysis was stratified by PCI indication and the effect of bivalirudin was modified (table 6).

Among STEMI patients ( $\mathrm{n}=7696$ or $13.8 \%)$ major bleeding rates did not differ significantly between anticoagulants $(\mathrm{OR}=1.8$, CI 0.54 to $6.04, \mathrm{p}=0.34)$ when controlling for the added use of 2B3A inhibitors. Among NSTEMI patients $(\mathrm{n}=26485$ or $47.5 \%)$ bivalirudin was significantly associated with fewer major bleeding outcomes $(\mathrm{OR}=0.21$, CI 0.08 to $0.57, \mathrm{p}=0.002)$. For patients with Stable Angina ( $\mathrm{n}=21573$ or $38.7 \%)$, bivalirudin was also significantly associated with less bleeding $(\mathrm{OR}=0.14$, CI 0.03 to $0.78, p=0.02$ ). The effect of a closure device as protective against bleeding risk was only observed among STEMI patients and an interaction between anticoagulant and closure device was only observed among NSTEMI and Stable Angina patients $(p=0.001$ and $\mathrm{p}=0.013$, respectively). The added benefit of device was greatest among female bivalirudin patients (figure 4).

\section{DISCUSSION}

As a direct thrombin inhibitor, bivalirudin is considered as an alternative to unfractionated heparin for higher risk patients undergoing PCI. ${ }^{16-20}$ Several studies demonstrate the effectiveness of bivalirudin over heparin and device closure over compression among women, the elderly, and STEMI patients. ${ }^{12} 1415$ 21-23 Our findings extend these studies by showing that there is a benefit with bivalirudin but it is modified by MI risk and the utilisation of 2B3A inhibitors. The HORIZONS trial suggested, for patients on a study protocol, that bivalirudin was superior to heparin. ${ }^{20}$ However, our data suggest this is not the case among STEMI patients. In clinical practice, 2B3A inhibitors are used liberally, and in the 
Table 4 Bleeding rates for all patients by various risk group and treatment strategy

\begin{tabular}{|c|c|c|c|c|c|c|}
\hline Group & $\begin{array}{l}\text { Heparin } \\
\text { +compress n (\%) }\end{array}$ & $\begin{array}{l}\text { Heparin } \\
\text { +device } \mathrm{n}(\%)\end{array}$ & $\begin{array}{l}{ }^{*} \mathrm{ARD}(\mathrm{RRR}) \\
\text { [NNT] }\end{array}$ & $\begin{array}{l}\text { Bival+compress } \\
\text { n (\%) }\end{array}$ & $\begin{array}{l}\text { Bival } \\
\text { +device } \\
\text { n (\%) }\end{array}$ & $\begin{array}{l}\text { †ARD (RRR) } \\
\text { [NNT] }\end{array}$ \\
\hline Overall & $612(2.9)$ & $169(2.6)$ & $0.3(0.10)$ [333] & 253 (1.9) & $44(1.0)$ & $0.8(0.42)[125]$ \\
\hline Male & $287(2.0)$ & $70(1.6)$ & $0.4(0.20)[250]$ & $106(1.2)$ & $24(0.8)$ & $0.4(0.33)[250]$ \\
\hline Female & $325(4.6)$ & $99(4.5)$ & $0.1(0.02)[1000]$ & 147 (3.2) & $20(1.3)$ & $1.9(0.59)[53]$ \\
\hline \multicolumn{7}{|c|}{ 2B3A inhibitors } \\
\hline STEMI & $228(8.1)$ & $53(5.9)$ & $2.2(0.27)[45]$ & $16(7.5)$ & $7(7.0)$ & $0.5(0.07)$ [200] \\
\hline NSTEMI & $160(4.0)$ & $57(3.7)$ & $0.3(0.08)$ [333] & $17(4.0)$ & $6(3.4)$ & $0.6(0.15)[167]$ \\
\hline $\begin{array}{l}\text { Stable } \\
\text { Angina }\end{array}$ & $66(2.4)$ & $13(1.5)$ & $0.9(0.37)[111]$ & $14(3.6)$ & $2(2.0)$ & $1.6(0.44)[62]$ \\
\hline \multicolumn{7}{|c|}{ No 2B3A inhibitors } \\
\hline STEMI & $40(4.0)$ & $5(2.5)$ & $1.5(0.37)[66]$ & $23(4.7)$ & $10(4.0)$ & $0.7(0.15)[143]$ \\
\hline NSTEMI & 69 (1.2) & $29(1.6)$ & $0.4(0.33)$ [250] & $100(1.9)$ & $14(0.7)$ & $1.2(0.63)[83]$ \\
\hline $\begin{array}{l}\text { Stable } \\
\text { Angina }\end{array}$ & $49(0.9)$ & $12(1.0)$ & $0.1(0.11)$ [1000] & 83 (1.3) & $5(0.3)$ & $1.0(0.76)[100]$ \\
\hline
\end{tabular}

current registry over $67 \%$ of STEMI patients received them. A majority was used $(92 \%)$ in STEMI patients receiving heparin. However, their use was greater with heparin in NSTEMI and Stable Angina groups and bivalirudin retained an advantage in lowering bleeding risk. The differentially high utilisation of 2B3A with heparin compared with bivalirudin in STEMI patients may be enough to mask an effect for bivalirudin.
For NSTEMI and Stable Angina patients, bivalirudin was superior to heparin even after adjusting for confounding factors. Many of these patients, (more than $30 \%$ ) also received $2 \mathrm{~B} 3 \mathrm{~A}$ inhibitors. The magnitude of its effect on major bleeding was extremely large, in some cases four times the rate of bleeding compared to patients not receiving 2B3A inhibitors. Major bleeding following PCI is strongly associated with increased

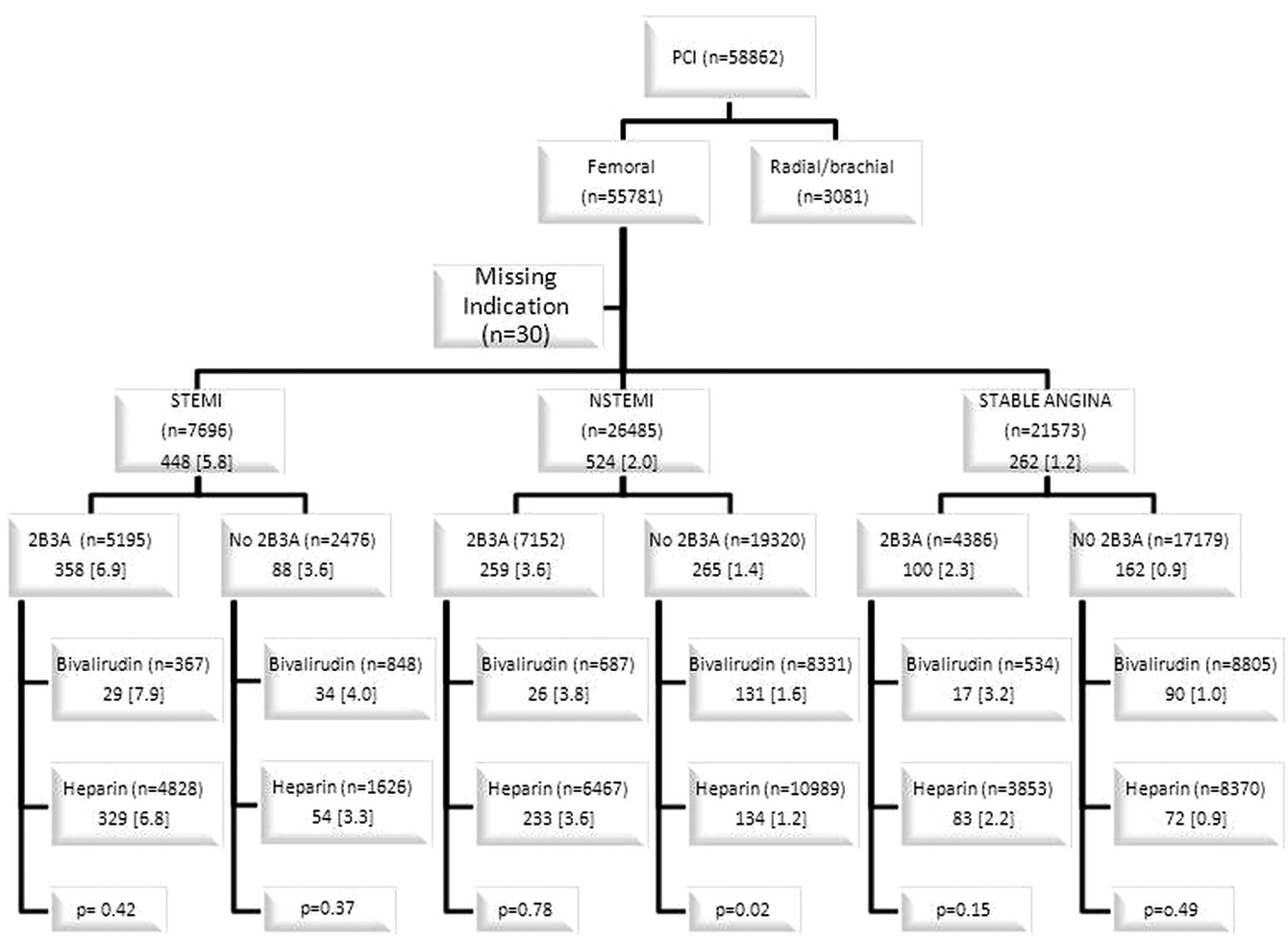

Figure 2 Major bleeding rates by risk category and GPI utilisation: numbers are reported as $\mathrm{n}(\%)$. 
Table 5 Final regression model

\begin{tabular}{|c|c|c|c|c|c|c|c|c|}
\hline & $\boldsymbol{\beta}$ & SE & Wald & df & p Value & OR & Lower $\mathrm{Cl}$ & Upper CI \\
\hline Sex (M1/F2) & 0.764 & 0.064 & 140.90 & 1 & 0.000 & 2.15 & 1.89 & 2.43 \\
\hline Age & 0.033 & 0.003 & 119.86 & 1 & 0.000 & 1.03 & 1.03 & 1.04 \\
\hline Current smoker (no 0/yes 1) & 0.229 & 0.078 & 8.61 & 1 & 0.003 & 1.26 & 1.08 & 1.47 \\
\hline Hypertension (no 0/yes 1) & 0.272 & 0.096 & 8.06 & 1 & 0.005 & 1.31 & 1.09 & 1.59 \\
\hline Chronic lung disease (no 0/yes 1 & 0.431 & 0.074 & 34.15 & 1 & 0.000 & 1.54 & 1.33 & 1.78 \\
\hline Kidney disease (no 0/yes 1 ) & 0.747 & 0.181 & 17.03 & 1 & 0.000 & 2.11 & 1.48 & 3.01 \\
\hline Prior $\mathrm{PCl}$ (no 0/yes 1) & -0.471 & 0.071 & 43.98 & 1 & 0.000 & 0.62 & 0.54 & 0.72 \\
\hline PCI indication (STEMI1/NSTEMI 2/stable 3) & -0.675 & 0.048 & 201.01 & 1 & 0.000 & 0.51 & 0.46 & 0.56 \\
\hline Anticoagulant (heparin 0/bivalirudin 1) & -1.002 & 0.358 & 7.85 & 1 & 0.005 & 0.37 & 0.18 & 0.74 \\
\hline 2B3A (no 0/yes 1) & 1.011 & 0.075 & 180.71 & 1 & 0.000 & 2.75 & 2.37 & 3.18 \\
\hline Closure method (device1/compression 2) & 0.145 & 0.167 & 21.19 & 1 & 0.11 & 1.16 & 0.97 & 1.38 \\
\hline Closure method by anticoagulant & 0.624 & 0.190 & 10.82 & 1 & 0.001 & 1.87 & 1.28 & 2.71 \\
\hline Constant & -6.588 & 0.399 & 361.54 & 1 & 0.000 & 0.001 & & \\
\hline
\end{tabular}

mortality risk ${ }^{17}$ and the addition of 2B3A inhibitors should be used cautiously. The risk benefit ratio of adding 2B3A inhibitors may be greater than previously appreciated.

We observed an overall interaction for closure device and anticoagulant. The device had a greater impact on bleeding among those treated with bivalirudin and a larger magnitude of effect among women. For women, as compared with men, the rate of major bleeding was three times lower with device than with compression and the slope of the decline due to device was significantly greater in bivalirudin, as compared with heparin, patients. This interaction may be due to the different mechanism of action by bivalirudin within the clotting cascade thereby causing the closure by device to be more effective.

Our data showed women to be at significantly higher risk of bleeding than men in every risk category. They were greatly disadvantaged in the STEMI group of patients receiving 2B3A inhibitors. However, even in the lowest risk groups (Stable Angina with no 2B3A), women had significantly higher rates of bleeding then men, similarly observed in other studies. ${ }^{24} 25$ We further

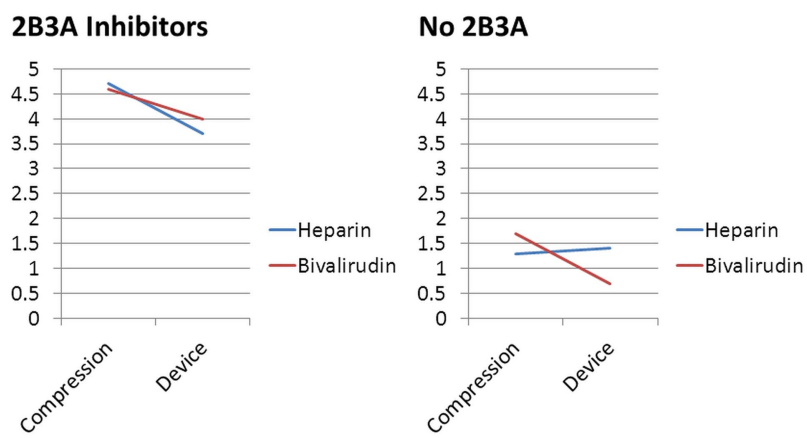

Figure 3 Bleeding rates by anticoagulant stratified for GPI utilisation: interaction between anticoagulant and closure method. observed that a treatment strategy of bivalirudin and closure device was particularly advantageous for these female patients. Bivalirudin and closure device narrowed the gender gap for bleeding significantly for higher risk groups and in the lower risk category, eliminating the disadvantage altogether. Optimising therapy requires further consideration of these lower risk groups. Our findings are consistent with another study showing significant benefit of bivalirudin in lower-risk patients. ${ }^{16}$

Another large effect was the protective effect of prior PCI observed in this study. This can be explained by several selective factors and has been reported in other studies. ${ }^{20}$ Patients of prior PCI have been exposed previously to higher doses of anticoagulants. They are more likely to tolerate these doses and are therefore more resistant to bleeding than patients who have not had a prior procedure. Separate from patient factors, physicians select patients out of the risk category by opting for procedures based on other bleeding-risk criteria such as the presence of anaemia and the history of bleeding. After adjustment for other confounding factors in our registry, this selection factor remained strong and explains the protective effect in our data.

A limitation to these findings is the retrospective nature of the data. Although the data were analysed retrospectively it was collected prospective and included all patients consecutively presenting for interventions within this national system. Unlike that of trial protocols, these findings reflect real-world practice. We also have to consider that there are additional confounding factors that may have differed between the anticoagulant groups, as well as between those receiving and not receiving 2B3A inhibitors that we were not able to control for with this registry. Lastly, a potential disadvantage for heparin due to varying dosing regimens was considered. However, heparin administration for the PCI procedures in this database, were per physician discretion under current standard recommendations: an initial bolus dose of 70$100 \mathrm{U} / \mathrm{kg}$ body weight followed by additional boluses 
Table 6 Final regression model highlighting the bivalirudin effect across $\mathrm{PCl}$ indications

\begin{tabular}{|c|c|c|c|c|c|c|c|c|}
\hline & $\boldsymbol{\beta}$ & SE & Wald & df & p Value & OR & Lower $\mathbf{C l}$ & Upper Cl \\
\hline \multicolumn{9}{|l|}{ STEMI } \\
\hline $\begin{array}{l}\text { Anticoagulant (heparin 0/bivalirudin 1) } \\
\text { NSTEMI }\end{array}$ & 0.589 & 0.62 & 0.9 & 1 & 0.340 & 1.80 & 0.54 & 6.04 \\
\hline Anticoagulant (heparin 0/bivalirudin 1) & -1.57 & 0.52 & 9.2 & 1 & 0.002 & 0.21 & 0.07 & 0.57 \\
\hline \multicolumn{9}{|l|}{ Stable Angina } \\
\hline Anticoagulant (heparin 0/bivalirudin 1) & -1.96 & 0.88 & 5.0 & 1 & 0.025 & 0.014 & 0.02 & 0.78 \\
\hline
\end{tabular}

Adjusted for confounding variables from table 5 .

NSTEMI, non-ST segment elevation myocardial infarction; STEMI, ST segment elevation myocardial infarction.

under activated clotting time guidance. ${ }^{26}$ Results of the ISAR-REACT 3A trial indicate that a reduced dose of heparin can be used with confidence. ${ }^{27}$ Other studies suggest that low-dose heparin does not reduce PCI-related bleeding. ${ }^{28}$ Although the heparin dosing regimens used for procedures in this database may vary across the standard range and by indication, per ACC/ AHA guidelines, they are based on the current clinical practice experience in cardiology community centres in the USA. This is also the case for dosing of 2B3A inhibitors and bivalirudin. Therefore, these comparative results are reflective of real-world difficulties in reducing major bleeding complications and the findings support a recommendation of routine use of bivalirudin rather than selective use.

The data for these findings highlight the most recent clinical practices thus published on the topic (2011/ 2012). The findings are robust (58 000patients) and represent a large national cross section of multiple community hospitals.

\section{CONCLUSION}

This robust analysis of real-world clinical data demonstrates a substantial treatment effect on bleeding risk with bivalirudin and device and that all groups of patients, regardless of risk category, benefit from reduction strategies for major bleeding. The hazards of 2B3A

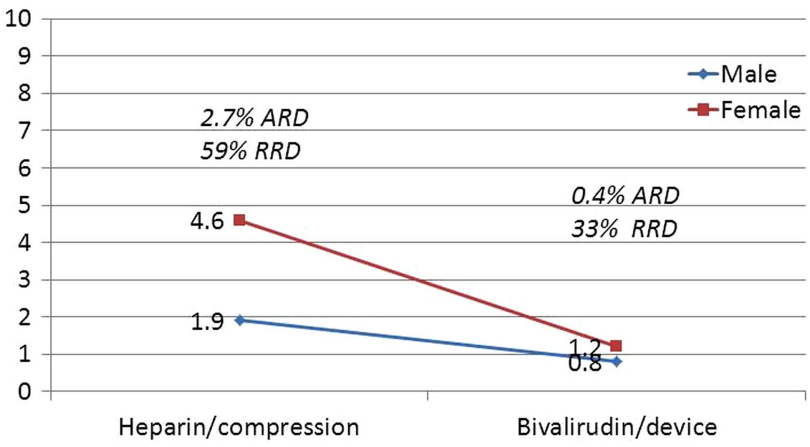

Figure 4 Gender gap in bleeding rates-combined bivalirudin/closure strategy eliminating the large bleeding gap between men and women that exist with a heparin strategy (from a $2.7 \%$ to a $0.4 \%$ absolute difference). are substantial and the risk benefit ratio may not justify their use in lower risk patients. The increased risk of bleeding due to female gender may be modified significantly with the strategy of bivalirudin and device.

Contributors All authors have made substantial contributions to the conception or design of the work and the acquisition of the study data. DRD and KRB have also contributed significantly to the analysis and interpretation of data for the work; all authors have drafted the work or revising it critically for important intellectual content; give final approval of the version to be published; and agree to be accountable for all aspects of the work in ensuring that questions related to the accuracy or integrity of any part of the work are appropriately investigated and resolved.

Funding This research received no specific grant from any funding agency in the public, commercial or not-for-profit sectors.

\section{Competing interests None.}

Ethics approval This study was approved on 11-9-2011 by the Genesys Health System Institutional Review Board.

Provenance and peer review Not commissioned; externally peer reviewed.

Data sharing statement No additional data are available.

Open Access This is an Open Access article distributed in accordance with the Creative Commons Attribution Non Commercial (CC BY-NC 3.0) license, which permits others to distribute, remix, adapt, build upon this work noncommercially, and license their derivative works on different terms, provided the original work is properly cited and the use is non-commercial. See: http:// creativecommons.org/licenses/by-nc/3.0/

\section{REFERENCES}

1. Verheugt FW, Steinhubl SR, Hamon M, et al. Incidence, prognostic impact, and influence of antithrombotic therapy on access and non-access site bleeding in percutaneous coronary intervention. JACC Cardiovasc Interv 2011;4:191-7.

2. Vavalle JP, Rao SV. Impact of bleeding complications on outcomes after percutaneous coronary interventions. Interv Cardiol 2009;1:51-62.

3. Tavris DR, Wang Y, Jacobs S, et al. Bleeding and Vascular complications at the femoral access site following percutaneous coronary intervention (PCOI): an evaluation of hemostasis strategies. $J$ Invasive Cardiol 2012;24:328-34.

4. Lincoff AM, Bittl JA, Harrington RA, et al:; REPLACE-2 Investigators. Bivalirudin and provisional glycoprotein IIB/IIla blockade compared with heparin and planned glycoprotein Ilb/llla blockade during percutaneous coronary intervention: REPLACE-2 randomized trial. JAMA 2003;289:853-63.

5. Stone GW, McLaurin BT, Cox DA, et al.; ACUITY Investigators. Bivalirudin for patients with acute coronary syndromes. NEJM 2006;355:2203-16.

6. Stone GW, Witzenbichler B, Guagliumi G, et al:; HORIZONS-AMI Trial Investigators. Bivalirudin during primary $\mathrm{PCl}$ in acute myocardial infarction. NEJM 2008;358:2218-30.

7. Parodi G, Antoniucci D, Nikolsky E, et al. Impact of bivalirudin therapy in high-risk patients with acute myocardial infarction: 1-year results from the HORIZONS-AMI (Harmonizing Outcomes with 
REvasculariZationON and Stents in Acute Myocardial infarction) trial. JACC Cardiovasc Interv 2010;3:796-802.

8. Ndrepepa G, Neumann FJ, Deliargyris EN, et al. Bivalirudin versus heparin plus a glycoprotein Ilb/llla inhibitor in patients with non-ST-segment elevation myocardial infarction undergoing percutaneous coronary intervention after clopidogrel pretreatment: pooled analysis form the ACUITY and ISAR-REACT 4 trials. Circ Cardiovasc Interv 2012;5:705-12.

9. Capranzano P, Dangas G. Bivalirudin for primary percutaneous coronary intervention in acute myocardial infarction: the HORIZANS-AMI trial. Expert Rev Cardiovasc Ther 2012;10:411-22.

10. Shelton R, Eftychiou $\mathrm{C}$, Somers $\mathrm{K}$, et al. Bivalirudin in patients undergoing primary percutaneous coronary intervention for acute ST-elevation myocardial infarction: outcomes in a large real-world population. Eurolntervention 2013;9:118-24.

11. Sanborn TA, Ebrahimi R, Manoukian SV, et al. Impact of femoral vascular closure devices and antithrombotic therapy on access site bleeding in acute coronary syndromes: the acute catheterization and urgent intervention triage strategy (ACUITY) trial. Circ Cardiovasc Interv 2010;3:57-62.

12. Marso SP, Amin AP, House JA, et al. Association between use of bleeding avoidance strategies and risk of periprocedural bleeding among patients undergoing percutaneous coronary intervention. JAMA 2010;303:2156-64.

13. Pinto DS, Ogbonnaya A, Sherman SA, et al. Bivalirudin therapy is associated with improved clinical and economic outcomes in ST-elevation myocardial infarction patients undergoing percutaneous coronary intervention: results from an observational database. Circ Cardiovasc Qual Outcomes 2012;5:52-61.

14. Pocock SJ, Mehran R, Clayton TC, et al. Prognostic modeling of individual patient risk and mortality impact of ischemic and hemorrhagic complications: assessment from the Acute Catheterization and Urgent Intervention Triage Strategy trial. Circulation 2010;121:43-51.

15. Anderson JL, Adams CD, Antman EM, et al.; 2011 WRITING GROUP MEMBERS; ACCF/AHA TASK FORCE MEMBERS. ACC/ AHA 2007 guidelines for the management of patients with unstable angina/non-ST-elevation myocardial infarction. A report of the American College of Cardiology/American Heart Association task force on practice guidelines. Circulation 2007;116:e148-304.

16. lijima R, Ndrepepa G, Mehilli J, et al. Profile of bleeding and ischemic complications with bivalirudin and unfractionated heparin after percutaneous coronary intervention. Eur Heart $J$ 2009;30:290-6.

17. Mehran R, Pocock S, Nikolsky E, et al. Impact of bleeding on mortality after percutaneous coronary intervention results from a patient-level pooled analysis of the REPLACE-2 (randomized evaluation of $\mathrm{PCl}$ linking angiomax to reduced clinical events), ACUITY (acute catheterization and urgent intervention triage strategy), and HORIZONS-AMI (harmonizing outcomes with revascularization and stents in acute myocardial infarction) trials. JACC Cardiovasc Interv 2011;4:654-64.
18. Lopes RD, Alexander KP, Manoukian SV, et al. Advanced age, antithrombotic strategy and bleeding in non-ST-segment elevation acute coronary syndromes: results from the ACUITY (Acute Catheterization and Urgent Intervention Triage Strategy) trial. J Am Coll Cardiol 2009;53:1021-30.

19. Levine GN, Bates ER, Blankenship JC, et al. 2011 ACCF/AHA/SCA Guideline for percutaneous coronary intervention. J Am Coll Cardiol 2011;58:e44-122.

20. Shah A, Feldman DN. Outcome of the HORIZONS-AMI trial: bivalirudin enhances long-term survival in patients with ST-elevation myocardial infarction undergoing angioplasty. Vasc Health Risk Manag 2012;8:115-23.

21. Kumar D, Dangas G, Mehran R, et al. Comparison of Bivalirudin versus bivalirudin plus glycoprotein Ilb/llla inhibitor versus heparin plus glycoprotein Ilb/llla inhibitor in patients with acute coronary syndromes having percutaneous intervention for narrowed saphenous vein aorto-coronary grafts (the ACUITY trial investigators). Am J Cardiol 2010;106:941-5.

22. Lansky AJ, Mehran R, Cristea E, et al. Impact of gender and antithrombin strategy on early and late clinical outcomes in patients with non-ST-elevation acute coronary syndromes (from the ACUITY trial). Am J Cardiol 2009;103:1196-203.

23. Anderson ML, Peterson ED, Brennan JM, et al. Short-and long-term outcomes of coronary stenting in women versus men: results from the national cardiovascular data registry centers for Medicare \& Medicaid services cohort. Circulation 2012;126: 2190-9.

24. Argulian E, Patel AD, Abramson JL, et al. Gender differences in short-term cardio vascular outcomes after percutaneous coronary interventions. Am J Cardiol 2006;98:48-53.

25. Chacko M, Lincoff AM, Wolski KE, et al. Ischemic and bleeding outcomes in women treated with bivalirudin during percutaneous coronary intervention: a subgroup analysis of the Randomized Evaluation in PCI Linking Angiomax to Reduced Clinical Events (REPLACE-2) trial. Am Hear J 2006;151:1032. E1-7.

26. Anderson JL, Adams CD, Antman EM. ACC/AHA 2007 guidelines for the management of patients with unstable angina/non ST-elevation myocardial infarction: a report of the American College of Cardiology/American Heart Association Task Force on Practice Guidelines (Writing Committee to Revise the 2002 Guidelines for the Management of Patients With Unstable Angina/Non ST-elevation Myocardial Infarction). J Am Coll Cardiol 2007;50:e1-157.

27. Schulz S, Mehilli J, Neumann FJ, et al. Intracoronary Stenting and Antithrombotic Regimen: Rapid Early Action for Coronary Treatment (ISAR-REACT) 3A Trial Investigators. ISAR-REACT 3A: A study of reduced dose of unfractionated heparin in biomarker negative patients undergoing percutaneous coronary intervention. Eur Heart $J$ 2010;31:2482-91.

28. Steg PG, Jolly SS, Mehta SR, et al. Low-Dose vs Standard-Dose Unfractionated Heparin for Percutaneous Coronary Intervention in Acute Coronary Syndrsomes Treated With Fondaparinux: The FUTURA/OASIS-8 Randomized Trial. JAMA 2010;304:1339-49. 